\title{
Luto e enfrentamento em portadores de esclerose múltipla: Diálogo com a teoria de Kübler-Ross
}

\author{
Maria Cristina Itagiba-Fonseca \\ Sabrina Martins Barroso
}

\section{RESUMO}

A Esclerose Múltipla (EM) é uma doença crônica e progressiva, que causa perdas motoras, sensoriais e psicológicas. Objetivo: Compreender o processo de luto e enfrentamento de pessoas com esclerose múltipla, em diferentes períodos do diagnóstico, sob enfoque das proposições teóricas de Kübler-Ross sobre o processo de luto. Método: Foram realizadas entrevistas semiestruturadas e foi feita a aplicação das pranchas um e 11 do Teste de Apercepção Temática a três mulheres, uma delas estava em investigação diagnóstica para EM, uma tinha diagnóstico de EM há um ano e a terceira havia sido diagnosticada com EM há cinco anos. Utilizou-se análise de conteúdo temática para organização dos dados e a teoria do luto de Kübler-Ross para analisá-los. Resultados: Diferenças na forma como cada participante lidava com a EM puderam ser observadas. As participantes com diferentes períodos de diagnóstico/investigação vivenciavam fases distintas do processo de luto e utilizavam diferentes tipos de estratégias de enfrentamento. Conclusões: 0 adoecimento conduz ao luto, que pode ser uma forma para realizar o enfrentamento e ressignificar a vida na nova condição.

Palavras-chaves: luto; enfrentamento; esclerose múltipla; Teste de Apercepção Temática

\section{ABSTRACT \\ Grief and coping in patients with multiple sclerosis: Dialogue with Kübler-Ross theory}

Multiple Sclerosis (MS) is a chronic and progressive disease that causes motor, sensory and psychological losses. Objective: To understand the process of grief and coping in people with multiple sclerosis, at different stages of diagnosis, based on Kübler-Ross' theoretical propositions of grief. Method: Semi-structured interview and application of pictures 1 and 11 of the Thematic Apperception Test to three women, one in diagnostic investigation for MS, one diagnosed with MS a year ago and the third has been diagnosed with MS for five years. We used thematic content analysis for data organization and the Kübler-Ross grief theory to analyze them. Results: Differences in the way each participant felt MS could be observed. The participants at different stages of diagnosis/investigation experienced a different phase of the grief process and used different types of coping strategies. Conclusions: Illness leads to mourning, which can be a coping strategy to re-signify life in the new condition.

Keywords: grief; coping; multiple sclerosis; Thematic Apperception Test

Múltiplos Fatores, tais como o contexto histórico, o momento da vida, a interligação e interdependência entre os seres humanos e a possibilidade de intervenção na tomada de decisões, permeiam o ciclo da vida. Segundo Elder Jr. (1994), existem significados sociais em cada etapa do desenvolvimento, que incluem a expectativa de acontecimentos próprios para cada idade. Neste sentido, a fase adulta seria o período destinado à construção e consolidação na carreira profissional e à formação familiar.

A Esclerose Múltipla (EM) é uma doença neurológica, crônica e autoimune, caracterizada pela ação inflamatória e destrutiva nos axônios mielinizados, gerando lesões no Sistema Ner-

\section{Sobre os Autores}

M. C. I. F.

orcid.org/0000-0002-3785-7054

Universidade Federal de São

Paulo (UNIFESP) - São Paulo, SP maritagiba@hotmail.com

S. M. B.

orcid.org/0000-0003-1759-9681

Universidade Federal do

Triângulo Mineiro (UFTM) -

Uberaba, MG

sabrina@psicologia.uftm.edu.br

\section{Direitos Autorais}

Este é um artigo de acesso aberto e pode ser reproduzido livremente, distribuído,

transmitido ou modificado, por qualquer pessoa desde que usado sem fins comerciais. 0 trabalho é disponibilizado sob a licença Creative Commons CCBY-NC. 


\section{WIIITERACÃO EM ET. PSICOLOGIA}

voso Central (SNC) (D’Amico, Patti, Zanghì, \& Zappia, 2016). As lesões afetam os axônios irreversivelmente e geram perdas neurológicas persistentes e incapacitantes. Os sinais e sintomas da EM são variados, afetando aspectos motores, sensoriais, visuais, vesicais e/ou intestinais, sexuais, cognitivos e emocionais (Frankel, 2010; Giovannoni et al., 2016).

A EM é uma doença que apresenta grande variação de seu perfil imunopatológico, genético, demográfico, clínico e de resposta terapêutica (Comini-Frota, Vasconcelos, \& Mendes, 2017). O curso da EM é altamente variável e seu início é mais frequente na idade entre os 20 e os 45 anos, embora também possa surgir em crianças e idosos. Sua prevalência no Brasil está estimada em 15 a 27,2 casos para cada 100.000 habitantes (Finkelsztejn, Lopes, Noal, \& Finkelsztejn, 2014), sendo duas vezes mais frequente em mulheres do que em homens (Goldenberg, 2012).

Segundo Goldenberg (2012), o diagnóstico de EM é feito por meio das evidências clínicas associadas aos exames de imagem e laboratoriais. Tal avaliação considera a presença de um ou mais dos três principais critérios diagnósticos, sendo eles: evidências de pelo menos duas lesões diferentes na substância branca do SNC; pelo menos dois episódios de surto diferentes no curso da doença; e/ou presença de inflamação crônica do SNC, determinada a partir da análise de Líquido Cefalorraquidiano.

Além da angústia pelo longo e complexo processo de diagnóstico, o caráter crônico da EM pode ser entendido como uma ruptura do ciclo esperado da vida. Genezini (2009) indica que a experiência de adoecimento representa um ataque ao corpo, não apenas físico, mas também simbólico. 0 adoecimento ameaça não apenas com a possibilidade da morte e a perda da saúde, mas pela transformação ou abandono de papeis sociais, profissionais e pessoais exercidos anteriormente, podendo desencadear um processo de luto. Para Parkes (1998), o luto é um processo psicossocial transitório, com impacto em toda a vida do ser humano, que ocorre a partir de evento traumático, seja este uma morte ou a perda da saúde e exige mudanças de concepções e reorganização dos papeis sociais.

Ao observar o processo vivido por pacientes terminais, Kübler-Ross propôs que a elaboração da vivência do luto passa por cinco fases: 1. Negação e Isolamento, 2. Revolta, 3. Barganha, 4. Depressão e 5. Aceitação. Cada fase contém características próprias e pode ocorrer de forma concomitante (Kessler \& Kübler-Ross, 2005; Kübler-Ross, 2008; Kübler-Ross \& Kessler, 2000). Embora haja controvérsias sobre a forma como a teoria foi concebida (Afonso \& Minayo, 2013), sobre a linearidade no processo de luto ou mesmo sobre a existência de sintomas de luto em vivência de adoecimento ou morte (Holland, 2014), a teoria de Kübler-Ross tem sido muito utilizada para tentar explicar como as pessoas lidam com suas perdas (Afonso \& Minayo, 2013).

Na proposta de Kübler-Ross (2008) ao iniciar a tentativa para lidar com uma perda, real ou antecipada, a pessoa pode vivenciar uma fase de isolamento ou negação desua condição. Em tal fase pode haver evitação de temas relacionados à doença como defesa temporária para enfrentar a perda da saúde. Podem surgir, ainda, sentimentos de raiva, revolta, sadismo, inconformismo, inveja e ressentimento em relação à doença, à família e à equipe de saúde. Essa é a fase chamada de revolta (Kübler-Ross, 2008; Simonetti, 2011). Ao não solucionar sua situação com a revolta, a pessoa que vivencia o luto pode tentar o estágio da barganha. Na barganha ocorre a negociação como busca para solução do sofrimento. São comuns manifestações religiosas e de esperança injustificada na tentativa de modificar o desfecho da doença. Porém, não se nega mais a chance da morte e/ou da mudança no estilo de vida, embora persista o desejo de continuidade de projetos futuros (Kessler \& Kübler-Ross, 2005; Kübler-Ross, 2008). Quando confrontado com a ineficiência da barganha, o indivíduo pode vivenciar o estágio da depressão. Nesse estágio, a perda está iminentemente presente na vida do indivíduo, isso provoca tristeza mas leva a uma percepção mais realista da situação. A depressão pode ser de natureza reativa, surgindo como consequência de uma perda já consumada, ou preparatória, antecipando uma situação iminente (Kübler-Ross, 2008; Simonetti, 2011). Ao aproximar-se da realidade, a pessoa pode chegar à fase de aceitação. Nessa fase compreende-se dos limites e possibilidades impostos pela situação (doença ou iminência da morte), tratamento e mudança de hábito. Como a percepção é mais realista, há maior flexibilidade emocional para lidar com a crise (Kübler-Ross, 2008). Contudo, a aceitação não representa ficar feliz, mas entender que a perda é concreta e que, ainda assim, pode-se continuar vivendo (Kessler \& Kübler-Ross, 2005).

Para doenças crônicas como a EM, o diagnóstico representa o início do processo de luto para o sujeito e sua família (Genezini, 2009). Na elaboração do luto de pacientes crônicos, o que se busca é a adaptação à sua nova condição restritiva (Schmidt \& Mata, 2008; Santos \& Sebastiani, 2001), o que passa pelo desenvolvimento de estratégias de enfretamento condizentes com sua condição e personalidade.

Lazarus e Folkman (1984) indicam que tais estratégias são práticas cognitivas e/ou comportamentais utilizadas em prol da adaptação a circunstâncias adversas. Tais estratégias podem focar-se na modificação da situação que deu origem à desordem, ou na emoção, em que se busca regular o estado emocional gerado pela condição estressora. Segundo Calandri, Graziano, Borghi e Bonino (2017), as estratégias de enfrentamento focadas nas emoções são as mais utilizadas por pessoas com EM. As estratégias de enfrentamento podem, também, contribuir com o processo de luto e ajusta- 


\section{H NTERAC̄öEM ET PSICOLOGIA}

mento psicológico em pessoas com EM, ocupando a aceitação um importante papel mediador nesse processo (Grech et al., 2016).

Calandri et al. (2017) apontam o diagnóstico da EM como gerador de muito sofrimento, devido ao caráter crônico, incurável e progressivo da patologia. Esse diagnóstico exige enfrentamento e adaptação à sua nova condição, podendo levar ao luto. Mas esse é um aspecto da EM ainda pouco investigado (Calandri et al., 2017; Uccelli et al., 2013; Grech et al., 2016). Visando contribuir para o desenvolvimento do tema, este estudo buscou compreender o processo de luto e enfrentamento de pessoas com EM em diferentes períodos do diagnóstico, sob enfoque das proposições teóricas de KüblerRoss.

\section{MÉTODO}

Estudo de caso de caráter qualitativo, realizado com a participação de três mulheres com idade entre 30 e 35 anos, vivenciando três momentos diferentes do diagnóstico da EM, acompanhadas no Ambulatório de Esclerose Múltipla do Hospital de Clínicas da Universidade Federal do Triângulo Mineiro. Uma das mulheres estava em investigação diagnóstica para $\mathrm{EM}$, as outras duas tinham diagnóstico definido há um ano e há cinco anos. As participantes foram nomeadas como Rosa, Tulipa e Margarida para manter o anonimato de suas identidades.

As participantes foram selecionadas após busca nos prontuários, considerando o período de tempo com relação ao diagnóstico e aproximação dos perfis (sexo, idade do início do diagnóstico, não ter comorbidades neurológicas e/ou psiquiátricas). As duas participantes já diagnosticadas com EM possuem o tipo Remitente-Recorrente (EMRR) da doença.

A coleta de dados foi realizada por meio de entrevista semiestruturada individual e da aplicação das pranchas 1 e 11 do Teste de Apercepção Temática (TAT). As entrevistas aconteceram em local e horário agendados com as participantes e abordaram características individuais, gostos e preferências, sintomas, tratamento, relações familiares, profissionais e sociais e sentimentos e atividades antes e após o surgimento dos sintomas e/ou diagnóstico da EM.

O TAT foi desenvolvido por Henry Murray, em 1938 e adaptado para o Brasil por Maria Cecilia de Vilhena M. Silva, em 1995 (Murray, 1943/2005). O teste é composto por 31 cartões com imagens para desencadear projeção quanto a temas pré-definidos. Scaduto (2016) e Inslegers et al. (2012) indicam que o TAT é uma medida com capacidade para identificar a complexidade das representações das pessoas, qualidade afetiva das representações, investimento emocional nos relacionamentos, valores e preceitos morais e entendi- mento de causalidade social. Estudos sobre propostas de correção do TAT e sua utilização em diferentes contextos podem ser encontrados em Scaduto e Barbieri (2013) e Scaduto (2016).

O uso do TAT visou complementar à entrevista e não avaliar a personalidade das participantes, adotando-se apenas os cartões 1 e 11, devido aos temas que abordam. Segundo Campos, Bach e Alvares (2003), a prancha 1 permite o reconhecimento da angústia e luto, imaturidade atual, relação com a autoridade, atitude diante do dever e ideal de ego, aquisição de conhecimento, dinâmica familiar e capacidade de realização e consecução dos objetivos propostos diante de nova situação. Enquanto a prancha 11 avalia as atitudes frente ao desconhecido, perigo e/ou instintos, capacidade organizativa do meio, formas de elaboração da angústias e ansiedade e representação simbólica para problemas.

Após a coleta dos dados todas as entrevistas foram transcritas e realizou-se a leitura flutuante do material, em busca de pontos de destaque para definição das categorias, segundo o referencial de análise de conteúdo proposto por Bardin (2010). A leitura flutuante permitiu identificar as categorias: revolta com a vida, sentimentos negativos, superproteção, mudanças profissionais, alterações nos papéis familiares, percepções irrealistas, estratégias de enfrentamento e ressignificação da vida. Em leitura detalhada e exaustiva do material percebeu-se a possibilidade de interpretação de algumas categorias como relacionadas ao processo de luto e optou-se por trabalhar com esse recorte interpretativo, sob referencial teórico de Kübler-Ross. O TAT foi interpretado de forma ideográfica e relacionado com a entrevista para tentar compreender o luto e o enfrentamento.

O projeto foi aprovado pelo Comitê de Ética em Pesquisa da Universidade Federal do Triângulo Mineiro (Protocolo 2461/2013) e todas as participantes assinaram o Termo de Consentimento Livre e Esclarecido.

\section{RESULTADOS E DISCUSSÃO}

\section{ROSA: O PERÍODO DE INVESTIGAÇÃO DIAGNÓSTICA}

Rosa, 32 anos, encontrava-se em investigação diagnóstica há quatro meses quando entrevistada. Possuía ensino médio completo, era solteira, economicamente ativa, natural de Frutal (MG) e residia em Uberaba (MG) com seus pais e irmãos. O sintoma que a levou a investigar a doença foi uma dor no olho direito, seguida por dores de cabeça e progressiva perda da visão. Esses sintomas duraram três meses e cessaram após internação para tratamento por pulsoterapia.

Ao longo da entrevista, Rosa aparentou estabilidade, fazendo uso de respostas superficiais, tentando normalizar as 


\section{-4* INTERACÃO EM LF PSICOLOGIA}

vivências relatadas. A doença não ocupou espaço em seu discurso. Esse comportamento, interpretado como negação, representa a primeira fase do processo de luto prevista por Kübler-Ross e foi percebido em falas como a referente à internação para investigação diagnóstica: "Foi tranquilo... foi até bom, porque faz os exames tudo diretim né?".

Rosa anula a possibilidade de ter EM, porém, para isso, faz-se necessário também anular outros aspectos de sua história. Ela não destaca nenhum evento memorável da sua infância "Minha infância foi normal também...", sua adolescência "Também não. [...] Não... nenhum fato assim... né?" ou vida adulta "Bom... tá sendo tranquilo, por enquanto... pretendo ficar tranquila... [Ri]". Contudo, ao responder ao TAT, as histórias apontaram parasentimentos, que podem relacionar-se às dúvidas sobre o diagnóstico e medo de ter EM.

Prancha 1 (latência 10s): [rindo] Nossa, sou horrível... fazer uma redação... Bom, esse personagem parece que tá bem pensativo, não sei, ele deve tá pensando assim... ah, acho que esse violino tá estragado, ele deve tá pensando "Como é que eu faço pra consertar ele?" Tá com semblante triste [risos]... Não sei se a estória tá boa não, mas... [risos, 7 segundos de silêncio] Bom, ele tá bem triste e... pensativo... [intervenção da entrevistadora: Que aconteceu?] Tentando ver como que ele vai fazer pra, no caso, se tiver estragado... [a mãe corta: ela quer saber o que aconteceu com ele, vamos supor se assim, tem... ele tá doente... como que vai fazer movimentar as mão] É pode ser... talvez ele, num... [mostrando a imagem pra mãe] não, mas aqui... do jeito que ele tá com as mãozinha... não tem como. Pra mim é isso, ele deve tá pensando em como ele vai fazer pra [36s de silêncio]. Bom, é isso... [risos, seguido de 8 segundos de silêncio] Bom o que eu acho é isso, então... não tem mais nada assim que eu veja, assim pra... só tem que terminar a estória né? Aliás, eu nem comecei... direito [risos, seguidos de 8 s silêncio]. Bom o que eu acho é isso, ele deve tá imaginando como é que ele vai fazer pra [pausa] consertar esse violino... A estória vai terminar [pausa de 7s] eu acho que ele vai consegui consertar esse violino e... aproveitar dele...

Prancha 11 (latência 24s): Essa imagem aqui parece uma... caverna? [questiona à entrevistadora] [entrevistadora: ah, pode ser uma caverna, se você quiser] [risos de ambas] Aiai... vamos supor que eu entrei nessa caverna... [risos] entrei nessa caverna e vô [pausa] tentá [pausa] saí dela [pausa 5 segundos]. [Voltando-se para a mãe] Mãe, vem cá, agora é uma caverna... [risos e pausa de 12s] Falei pra ela, vamo supor que eu entrei nessa caverna e agora tem que [pausa] tentá saí dela [pausa 8s]. [Mãe diz: Cê encontrou cobra, bisorro que Cê tem medo] Tamém [pausa] cobra, besorro, tô apavorada, [pausa] gritando. [risos seguidos de pausa] tentando me esconder atrás dessas pedras [pausa de 8s] Minha solução é gritar, pedí socorro... [Entrevistadora: Como que a estória termina?] [Mãe responde se afastando: cê achou um estradinha... ééé, rio... alguma coisa, vai continuar nesse rio aí pra você sair] [Entrevistadora: Esse é o final da sua mãe e o seu?] Entrar nesse rio aqui, não sei nadar [risos de todos], vô morrer afogada [Mãe: Morrer não... se vira aí] [risos da entrevistada] Ué, vamos supor que eu encontrei esse rio, nadei e tive uma saída sensacional! [risos].

As pausas e risos durante a construção das histórias evidenciam dificuldade e ansiedade diante da possibilidade da ruptura com o ideal de ego, relacionado à imagem de saúde. Além disso, diante do conflito e da dúvida, a história é concluída abruptamente, sem elaboração do conflito. Na resposta à prancha 11 , o pavor diante da possibilidade de adoecimento e morte se evidencia pelo conteúdo narrado, pausas, risos e, novamente, ausência de elaboração do conflito. A ausência de outros personagens que possam ajudar o herói e os pedidos de interferência feitos à mãe também podem ser indicativos das dificuldades para lidar com os conflitos. A mãe de Rosa torna-se a pessoa que expõe os medos e outros sentimentos próprios e da filha diante da experiência do possível adoecimento.

A presença e as intervenções da mãe, ora espontâneas, ora convidadas por Rosa, permitiram, ainda, questionar a proteção e a alteração dos papéis familiares. Diante da pergunta "Como era sua relação com sua família antes e agora durante esse período de investigação diagnóstica?", Rosa responde "Bom... essa família sempre foi... vamos dizer.. tranquila né?" [A mãe interrompe]: 'Não! De preocupação, né?! Normal assim... agora, em relação ao tratamento, a gente fica assim.. fica bem preocupada".

\section{TULIPA: UM ANO DE DIAGNÓSTICO}

Tulipa, 32 anos, possuía diagnóstico de EMRR há um ano quando participou da entrevista e lidava com sintomas há dois anos. É natural de João Pinheiro (MG), onde residia. Possuía ensino médio completo, estava casada há três anos e meio e não tinha filhos. Era economicamente ativa, porém avaliava a possibilidade de deixar o emprego em consequência das dificuldades da EM.

Relatou que os primeiros sintomas foram dores nos olhos e fotofobia, evoluindo para dores de cabeça e tontura, perda de sensibilidade e força dos membros superiores e inferiores. Durante a entrevista de Tulipa percebeu-se a dualidade saúde-doença que organizava sua vida. O período anterior à EM era significado como de saúde plena, enquanto o atual relaciona-se com o adoecimento.

Até 30 anos de idade eu não tomava remédio nem pra dor, sabe? Desde criancinha até os 30 anos eu nunca tinha ido num hospital. Agora depois que eu fui começar a sentir esses sintomas. Passei a sentir esses sintomas. (Em res- 


\section{H. INTERACÃO EM L PSICOLOGIA}

\section{posta à pergunta sobre como tem sido a vida adulta)}

Apesar de buscar acompanhamento médico, Tulipa vivenciou os sintomas por um ano antes de obter o diagnóstico. Durante esse período foi tratada com ansiolíticos, o que resultou em ressentimento com a demora e erro do médico sobre seu quadro clínico.

Aí eu procurei um neuro em João Pinheiro lá... e ele me disse que era cansaço, estresse, assim.. [...] Ele me passou assim medicamento pra eu dormi, calmante, remédio vermelho, assim, essas coisa. E eu tomei durante dois meses e não via resultado nenhum. [...] Aí eu perguntei ele, falei que queria uma coisa mais específica, eu queria saber o que que era, que eu via que não tava normal. Aí ele falou que não era nada não, mas que ia pedi uma ressonância só pra despreocupar mesmo, como diz ele, por desencargo de consciência. Aí eu vim cá, fiz a ressonância, ele viu já ficou, assim, um pouco sem graça, já viu que não tava normal. Aí ele falou que pra ter certeza se era esclerose... Ele foi me explicar da doença, até então eu nunca ouvi falar, tinha ouvido falar de esclerose. Ele foi me explicar um pouco, fiquei sem entender, fiquei com medo. Aí foi pra Patos, fiz... pediu exame, consultei com outro neuro, fiz o exame do liquor da medula né? Aí constou que era mesmo [Esclerose Múltipla]. (Em resposta à pergunta sobre história clínica)

Tulipa reconhece seus sintomas, mas acredita que a adesão ao tratamento poderá minimizar os efeitos da doença, o que pode representar uma forma de barganhar com o sofrimento. Em resposta à pergunta sobre sua percepção do tratamento, Tulipa responde:

Bom, hoje eu tô tomando assim o medicamento, eu tenho esperança que... que... seja bom, que melhore né? Eu tô tomando até então assim, eu senti duas vezes, depois que eu tô tomando [...] aí..e agora eu tô sentindo o meu ouvido zumbi, tá com um zumbido forte... Num tô ouvindo, mas tenho com esperança que... tá recente que tô tomando medicamento né? que eu possa melhorar, assim...

Tulipa relata dificuldades consequentes da condição da doença, mas demarca como maior dificuldade no trabalho, os efeitos sociais de sua condição e não possíveis limitações na execução de suas tarefas profissionais.

Não, mudança assim, eu tô trabalhando normal, mas eu sinto dificuldade, assim. [...] Eu já até comentei com meu marido que tô... eu vô ter que sair do meu serviço que eu sinto muito cansaço [...] porque às vezes a gente fica assim, às vezes, vira e mexe, às vezes a gente dá uma reclamadinha e é ruim né? Porque assim, trabalhar com o patrão, às vezes acha que num tá sentindo, então, eu, pra mim, às vezes pra prejudicar no emprego, eu prefiro sair (Em resposta à pergunta sobre mudanças no dia-a-dia após o adoecimento)
Tulipa atribui a aspectos externos o surgimento do sentimento de tristeza e distanciamento social que vivencia. Ao ser perguntada sobre mudanças em sua vida após o adoecimento, ela relata: "Eu tomo um remédio pra depressão que o outro medicamento que eu tomo deixa a gente mais deprimido, mais, assim né? Sensível". O isolamento social também surge na resposta à pergunta sobre a relação com a família antes e depois do diagnóstico: "Ah, sei lá, eu percebia que eu ia na casa da minha mãe com mais frequência, agora eu não vô muito. Assim, não sei, acho que tô desanimada de ir lá. Ai eu não vô muito, antes eu ia mais".

Além disso, o mecanismo de barganha também pôde ser observado no TAT, onde o esforço do personagem é recompensado pela "vitória" na vida na prancha 1.

Prancha 1 (latência 8s): Bom, eu tô vendo uma criança, saudável, olhando pra um violino e ele tá pensando que ele.. o sonho dele é tocar, mas ele tá com muita dificuldade [pausa 3s] mas como ele é uma criança ainda, tá jovem, ele tem toda possibilidade de aprender... pode fazer várias coisas, procurar profissionais, escolinhas, estudar bastante que ele ainda pode sê um grande violinista. [pausa 3s] É isso. [Entrevistadora: E como que a estória termina?] Hum, que ele cresceu, se tornou um adulto, né? $E$ conseguiu vencer seu sonho, que ele hoje é um grande violinista.

Enquanto as respostas à prancha 11 complementam os conteúdos expressos na entrevista, indicando vivências de isolamento, solidão e desamparo.

Prancha 11 (latência 10s): Peraí deixa eu entendê que que é essa imagem... que eu num tô entendendo nada... eu entendi que é uma cachoeira... [pausa 10s] parece um rio, tá parecendo umas pedras, um túnel [pausa 21s] o que é isso aqui? [Entrevistadora: Então, pode ser o que você quiser?] Ah, eu imaginei, sei lá... parece um lago, num é não? [Entrevistadora: E o que que aconteceu aqui nesse lugar?] [pausa 9s] É, aqui tá me parecendo uma cachoeira muito alta, uma água, um rio [pausa 14s] ixaa... [pausa 7s] tá e aí... [pausa 11s] [Entrevistadora: Nesse lugar que você conseguiu imaginar... o que aconteceu?] É, não... aqui tá me parecendo assim, uma cachoeira, um lugar feio, umas crateras, uns... sei lá, tá me lembrando um lugar triste, um lugar feio, escuro... porque esse lugar não é... [pausa 8s] eu tô querendo... [Entrevistadora: Você tem uma estória pra ele?] Ahh sei lá, não... [pausa] acho que não, uma estória pra ele... [pausa 13s] Bom, igual eu falei, eu tô me imaginando numa cachoeira, um lugar feio, um lugar que eu acho que as pessoas não devem ih, é um lugar perigoso, pode tê animais... agressivos, um lugar que parece tem morcego, não sei... [Entrevistadora: Como termina a estória?] Ai que é um lugar deserto, que não é frequentado por pessoas... 


\section{-4* INTERACÃO EM LF PSICOLOGIA}

\section{MARGARIDA: CINCO ANOS DE DIAGNÓSTICO}

Margarida, 34 anos, possuía diagnóstico de EMRR há aproximadamente cinco anos quando entrevistada. Estava casada há 15 anos e tinha dois filhos (15 e 11 anos). Possuía ensino médio completo, é natural e resistente de João Pinheiro (MG) e estava aposentada por invalidez há quatro anos.

O primeiro sintoma percebido foi a perda progressiva - e temporária - da visão. Relatou, também, a presença de vários outros sintomas, surtos e déficits ao longo dos cinco anos desde o diagnóstico. A evolução da doença trouxe à Margarida limitações, entre elas a necessidade de deixar o emprego, o que gerou ressentimento.

Antes eu trabalhava em escritório e... no escritório, eu mexia com a documentação de veículo né, então... a minha cabeça ali tava sempre voltada, focada naquilo ali, eu tinha por exemplo, cinquenta clientes, né? [...] Eu gostava, gostava do que eu fazia, gostava de atender meus clientes. Então assim, depois que eu adoeci... eu nem acreditei... porque, a minha cabeça era tipo assim... grandona, sabe? E depois ela foi ficando tão pitititica assim ó [sinaliza com as mãos o tamanhoreduzido]. Aí eu fico pensando, por quê? [silêncio 5s] Será que foi alguma coisa de errado que eu fiz? (Em resposta à pergunta sobre mudanças no dia-a-dia após o adoecimento)

Observam-se também dificuldades nas relações e papéis familiares, com sua autopercepção como mãe afetada pela EM. Por exemplo, quando perguntada sobre como é a relação com seus filhos, Margarida traz vivências de conflito.

Hoje, devido à doença, eles me... reprimem [hesitação] [intervenção da entrevistadora pedindo mais esclarecimentos]. Reprime, eles me gozam, me criticam, assim "ahh mãe... ahh não..." assim, desse jeito sabe, nesse tom "Não ó... a senhora é devagar demais!" [...] Desse jeito sabe? Aí eu penso tipo assim "vai passar... Vai passar!" Tipo assim, eu tento dá o meu melhor sabe [nome da entrevistadora]? Mas... eles, parece que eles não me conhecem, quer dizer, eles nem sabem né? Que eu tô tentando dá o meu melhor.

Margarida também mostra perceber uma superproteção familiar, que ela relaciona com uma noção de incapacidade e depreciação.

Igual, por exemplo, a minha mãe, ela tá muito preocupada. Ela me liga por tudo. Igual, esses dias eu estava passando mal, com dor de ouvido. Ela foi parar lá em casa no mesmo instante e "Margarida, que que foi, minha filha?" Nossa! aí foi ela, foi meu pai, foi meus irmão e eu "Gente! Calma, é uma dor de ouvido", "Não, Margarida, você tem esse trem" "Mãe, calma..." Entendeu? (Quando perguntada sobre como tem sido sua vida como adulta)

Nas respostas de Margarida pôde-se perceber elementos de superação da angustia inicial pelo diagnóstico e tentativas de lidar com a situação crônica da patologia. Tais tentativas já não apresentavam a ilusão do desaparecimento da EM, mas focavam na ressignificação da situação. Esses elementos podem ser exemplificados com a resposta de Margarida sobre sua percepção sobre o diagnóstico.

Hoje eu já penso diferente de quando eu descobri, né? Quando eu descobri eu assustei, como se diz, me senti pequena e por eu ter ficado, vamos dizer, acamada, por eu ter perdido a visão, por eu ter dificuldade motora, aí então pra mim foi difícil, mas hoje eu percebi se tomar a medicação certim, igual por exemplo, a doutora passa pra mim, né? E manter todos os cuidados necessários eu vô ter uma vida cumprida, num é coisa deu ter que chorar, deu ter que tentar, mas só depois deu ter feito isso tudinho que eu acabei de relatar.

Auxiliando no processo de aceitação, o recurso religioso surgiu como um aliado no enfrentamento da doença.

(...) É da mesma forma assim, como tudo na vida da gente passa, aí eu pego o meu tercinho, a minha santinha, vô lá na sala da tevê e ligo a tevê, né? E posto no canal católico, Século 21, que todo dia tem o terço, eu rezo o terço inteirim e a minha fé só... a fé, eu tenho muita fé, sabe [nome da entrevistadora]? (Em resposta à pergunta sobre como tem sido a vida adulta)

As respostas às pranchas do TAT abordaram múltiplos sentimentos, presença de angústia, distorções, conflitos familiares e vivências de dificuldades diversas, mas os sentimentos de impotência e onipotência cedem espaço à real potência e capacidade do sujeito e demonstram algum tipo de resolução. Demonstraram, ainda, percepções positivas e de itens de beleza.

Prancha 1 (latência 9s): Eu lembrei do J. M. [filho mais novo de Margarida] e lembrei que ele fica lá parado e eu fico maluca, né, porque minha cabecinha funciona é tipo a 120 , né? E ele tá lá parado assim, aí fico nervosa e eu falo pra ele "Filho, pelo amor de Deus, desenrola que a mamãe não aguenta mais esse dever..." E como hoje eu sô lenta, que eu já fui assim, né? Agora, hoje eu sô mais devagar, aí então, assim, parece que o meu coração palpita mais sabe [Nome da entrevistadora]? aí eu fico nervosa com ele, mas é que eu lembrei do meu filho... (intervenção da entrevistadora: Como a estória termina?) Ele fazendo o dever dele e fim.

Prancha 11 (latência 4 s): Eu já, lá na minha cidade, eu já saí andando aí eu já vi mais ou menos João Pinheiro dessa forma. [Entrevistadora: 0 que está acontecendo?] Olha, aqui tá aparecendo que tá acontecendo um tsunami, o que é isso [nome da entrevistadora] [Apontando algo na imagem]? [Entrevistadora: É o que você quiser] Aqui, pra 


\section{W'INTERACÃO EM ET PSICOLOGIA}

você vê, aqui parece que tem até uns dragões... é, [nome da entrevistadora], é isso? Parece que aqui tem uma abeIhinha que está grandona, mas é porque eu já tive muito pesadelo, [nome da entrevistadora], quando eu tinha por volta dos 11, 12 anos de idade e eu sonhava muito isso: fim do mundo. Aqui tá o fim do mundo? Não, só o escuro. Isso, mas assim é, é... o que me lembra é um sonho, um dos meus sonhos, não é sonho né? Pesadelos, me assustava muito... aham... agora hoje não, hoje eu sou mais, uma adulta, né? Mais centrada no que eu quero, nas coisas que são importantes pra mim... [Entrevistadora: $\mathrm{E}$ aqui? $\mathrm{O}$ que que tá acontecendo... nesse lugar? Como que desenrola essa estória?] [pausa 20s]. [Nome da entrevistadora], eu não entendi esse desenho ainda... nerr... isso são pedras! [Entrevistadora: Pode ser. É que não é um desenho fechado, imagina alguma coisa nele, ele só te dá algumas pistas...] Acho que aqui é um dragão saindo da fumaça, aqui tem uma abelhinha, tá vendo? Gigante, né? Agora aqui eu tô vendo, por exemplo, já tô imaginando a água, então assim, duas forças contrárias que eu tô vendo aqui, né... a água, tô vendo aqui o fogo, as chamas, então...as pedras, as pedras, a água do rio, acho que é isso que eu tô vendo [nome da entrevistadora]. [Entrevistadora: O que aconteceu nesse lugar, com esse monte de coisa?] Eu acho que foi um tsunami mesmo, mas tá tudo bem já. [Entrevistadora: Como a estória termina?] [Nome da entrevistadora], você é mau hein? Me ajuda... [ri] me ajuda, [nome da entrevistadora]. Então vamos lá, não, melhor... a abelhinha pousou na água, tomou um pouquinho de água, ela tá bem... o dragão cansou e voltou pra casa dele.

\section{UNINDO OS TRÊS CASOS}

A partir das entrevistas realizadas, foi possível perceber elementos comuns no processo de elaboração do luto. 0 diagnóstico da doença pode ser devastador para o sujeito, produzindo desorganização psíquica, colocando em xeque a capacidade de garantir a própria sobrevivência e explicitando a vulnerabilidade humana anteriormente ignorada (Schmidt \& Mata, 2008). O peso do diagnóstico pode ser observado na negação do tema por Rosa, na dicotomia de discurso entre saúde e doença de Tulipa e na fala direta de Margarida sobre suas dificuldades.

As limitações impostas pela EM forçam o sujeito a lidar com condições mais características de etapas posteriores do desenvolvimento humano (Haase, Lacerda, Lima, \& Lana-Peixoto, 2005). Mas Calandri et al. (2017) indicam que pessoas com EM podem encontrar novas significações para suas vidas, em especial se desenvolverem boas estratégias de enfrentamento. As entrevistadas mostraram esse embate quando confrontadas com a necessidade de abandonar seus empregos e se aposentar e/ou ser foco de preocupação e cuidados familiares, o que não é esperado para a fase adulta da vida.
A teoria de luto de Kübler-Ross espera que as pessoas signifiquem suas perdas de forma distinta, podendo passar por fases até ressignificar a experiência (Kübler-Ross, 2008; Kübler-Ross \& Kessler 2000; Kessler \& Kübler-Ross, 2005). A negação seria a primeira tentativa de anular a situação estressora. Essa seria uma possibilidade diante da incerteza do período de investigação diagnóstica para EM, como é o momento vivenciado por Rosa. Caso as etapas do luto prossigam como previsto por Kübler-Ross, quando não for mais possível negar a condição, a raiva e barganha podem surgir, como observado nas falas das participantes já diagnosticadas. A raiva esteve direcionada a si mesma no relato de Margarida, enquanto o discurso de Tulipa a destinava a outros. Elas diferiam também na barganha, que Tulipa direcionava ao tratamento e Margarida à religião.

O sentimento de impotência característico da fase de depressão também foi observado, na resposta de Tulipa à prancha 11 do TAT. Embora imbuído depotencial negativo, essa impotência pode ser um passo importante para a real aceitação e enfrentamento da situação (Holland, 2014; Kessler \& Kübler-Ross, 2005; Simonetti, 2011). Para Simonetti (2011), no adoecimento, a posição depressiva assume um caráter reativo à perda da saúde e representa uma etapa necessária à tarefa psíquica de enfrentamento. Se evitada, a depressão poderá trazer impacto negativo à adaptação do sujeito a sua nova condição. Assim como, se excessiva, passa a ser patológica.

Quando há aceitação, percebe-se que o sujeito desiste de tentar mudar a condição de adoecimento e passa a investir em estratégias emocionais. Na posição de enfrentamento há maior equilíbrio entre as fantasias de onipotência e impotência e alternância entre a desesperança vivida na posição depressiva e a agitação desorganizada, comum na etapa de revolta (Simonetti, 2011). No relato de Margarida, observamse mudanças em sua capacidade para tolerar as limitações provocadas pela EM e seu reconhecimento do processo de transformação de sua forma de lidar com o adoecimento e sua possibilidade de continuar se desenvolvendo. Margarida ainda enfrenta desafios e frustrações em seu cotidiano, no entanto, também demonstra capacidade de buscar recursos que permitam superar suas limitações. Esse processo de percepção mais realista da doença e seus impactos, permitindo ver pontos positivos e reconhecer a superação de desafios foram percebidos nas respostas de Margarida e no foco dado por ela em questões familiares ao responder a prancha 1 do TAT. Essas observações corroboram indicações de Bertolin, Pace, Kusumota, \& Haas (2011) sobre como o maior tempo decorrido do diagnóstico colabora para uma reavaliação positiva da doença e adoção de estratégias de enfrentamento focadas na emoção. Tais estratégias são descritas pelos autores como mais eficazes em situações de adoecimento crô- 


\section{H. INTERACÃO EM LF PSICOLOGIA}

nico e adotadas com maior frequência por mulheres, idosos e pessoas com mais tempo de adoecimento. Grench et al. (2015) investigaram as estratégias de enfrentamento adotadas por pessoas com EM e perceberam que estratégias adaptativas e realistas favoreciam melhor ajustamento psicológico e desempenho de funções executivas. Kessler e Kübler-Ross (2005) investigaram o processo de luto em pessoas com diagnóstico de Alzheimer e indicaram que tais pessoas vivenciam o processo de luto, mas pode ser que os comprometimentos da patologia se tornem muito severos antes que uma real aceitação da condição de adoecimento seja alcançada. Contudo, seus familiares vivenciam o processo de luto pela perda gradual do parente, até sua morte física, sendo observadas nesses familiares as mesmas fases de luto percebidas nas pessoas que enfrentam a morte.

Percebe-se que a EM, por seu caráter progressivo e incurável, exige do indivíduo estratégias voltadas às emoções (Calandri et al., 2017). Quando relacionadas à teoria do luto de Kübler-Ross, pode-se pensar que a negação e a barganha representam tentativas de utilização de estratégias de enfrentamento focadas no problema, enquanto a conscientização sobre o diagnóstico e mesmo o entristecimento reativo favorecem a adoção de estratégias voltadas para manejo das emoções. Simonetti (2011) destaca a posição de enfrentamento como processo final quando a adaptação ao adoecimento é bem-sucedida. Nesta posição, o indivíduo pode compreender que não está livre da doença, mas é livre para se posicionar diante dela, encarando-a com realismo diante de suas limitações e potencialidades.

Ao longo das entrevistas conduzidas nesse estudo pôdese observar que as relações e papéis familiares, profissionais e sociais passaram por alterações com o surgimento da EM ou de sua possibilidade. Observou-se, também, que cada participante lidava com seu diagnóstico ou investigação diagnóstica de forma distinta, sendo possível traçar paralelo com o processo de luto preconizado por Kübler-Ross. Embora não tivesse o mesmo foco do presente trabalho, o estudo de Ucelli, et al. (2013) sobre os pais de crianças com esclerose múltipla mostrou o impacto do diagnóstico nas relações familiares e como a adoção de estratégias de enfrentamento é importante para ressignificar as expectativas do paciente e de seus familiares.

\section{CONSIDERAÇÕES FINAIS}

0 presente estudo demonstra como pessoas enfrentam de forma distinta o diagnóstico de EM ou sua possibilidade, influenciando nessa diferença o tempo decorrido e as estratégias para manejo do luto pela perda da saúde. Esse trabaIho consistiu em um estudo de caso, realizado apenas com mulheres adultas em investigação ou com diagnóstico de EM e, por isso, seus resultados são restritos e não permitem falar sobre a vivência do luto e enfrentamento em pessoas com EM do sexo masculino ou pessoas com outras patologias. Apesar dessas limitações, as observações permitiram relacionar as estratégias de enfrentamento e o luto com a ressignificação necessária para lidar com uma condição crônica.

Espera-se, com os dados apresentados, lançar um novo olhar sobre o processo de luto, passando a entendê-lo como uma forma de lidar com uma quebra do ciclo esperado da vida e ressignificar seu papel pessoal e social diante de uma realidade não planejada. Outro ponto que merece destaque é que a adoção de uma forma mista de coleta de dados para tentar compreender a vivência de luto permitiu melhor compreensão do estado emocional das participantes, uma vez que a entrevista mostrou aspectos conscientemente processados, enquanto o TAT permitiu externalizar vivências de medo e esperanças de resolução fantasiosa da condição que desperta medo, mostrando o potencial do trabalho integrado de formas dessas formas de coleta.

\section{CONTRIBUIÇÃO DE CADA AUTOR}

M.C.I.F. fez a análise formal dos dados, a investigação e a tabulação dos dados. S.M.B. fez a revisão e edição inicial do manuscrito, a supervisão. M.C.I.F e S.M.B. fizeram a administração da pesquisa, a conceitualização das ideias, a metodologia, a preparação do rascunho original e a visualização da pesquisa.

\section{DECLARAÇÃO DE CONFLITOS DE INTERESSES}

As autoras declaram que não há conflitos de interesses no presente artigo.

\section{REFERÊNCIAS}

Afonso, S. B. C., \& Minayo, M. C. S. (2013). Uma releitura da obra de Elisabeth Kubler-Ross. Ciência \& Saúde Coletiva, 18(9), 2729-2732. doi: 10.1590/S141381232013000900028

Bardin, L. (2010). Análise do conteúdo. Lisboa: Edições 70.

Bertolin, D. C., Pace, A. E., Kusumota, L., \& Haas, V. (2011). Associação entre os modos de enfrentamento e as variáveis sociodemográficas de pessoas em hemodiálise crônica. Revista da Escola de Enfermagem da USP, 45(5),10701076. 62342011000500006

Calandri, E., Graziano, F., Borghi M., \& Bonino S. (2017). Coping strategies and adjustment to multiple sclerosis 


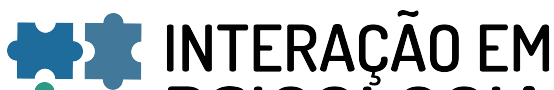 ET PSICOLOGIA}

among recently diagnosed patients: the mediating role of sense of coherence. Clinical Rehabilitation, 1-10. http://dx.doi.org/10.1177/0269215517695374

Campos, E. M. P., Bach, C., \& Alvares, M. (2003). Estados emocionais do paciente candidato a transplante de medula óssea. Psicologia: Teoria e Prática, 5(2), 23-36.

Comini-Frota, E. R., Vasconcelos, C. C. F., \& Mendes, M. F. (2017). Guideline for multiple sclerosis treatment in Brazil: Consensus from the Neuroimmunology Scientific Department of the Brazilian Academy of Neurology. Arquivos de Neuro-Psiquiatria, 75(1), 57-65. http://dx.doi.org/10.1590/0004-282x20160185

D’Amico, E., Patti, F., Zanghì, A., \& Zappia, M. (2016). A personalized approach in progressive multiple sclerosis: The current status of disease modifying therapies (DMTs) and future perspectives. International Journal of Molecular Sciences, 17(10),

1725-1739. http://dx.doi.org/10.3390/ijms17101725

Elder Jr, G.H. (1994). Time, human agency, and social change: Perspectives on the life course. Social Psychology Quarterly, 57(1), 4-15.

Frankel, D. I. (2010). Esclerose Múltipla. Em D. A. Umphred., Reabilitação neurológica (pp. 631-653). Rio de Janeiro: Elsevier.

Finkelsztejn, A., Lopes, J. S., Noal, J., \& Finkelsztejn, J. M. (2014). The prevalence of multiple sclerosis in Santa Maria, Rio Grande do Sul, Brazil. Arquivos de Neuro-Psiquiatria, 72(2), 104-106.

Genezini, D. (2009). Assistência ao luto. Em Academia Nacional de Cuidados Paliativos. Manual de cuidados paliativos (pp. 321-330). Rio de Janeiro, Brasil: Diagraphic.

Giovannoni, G. G., Butzkueven, H., Dhib-Jalbut, S., Hobart, J., Kobelt, G., Pepper, G., Sormani, M. P., Thalheim, C., Traboulsee, A, \&Vollmer, T. (2016). Brain health: Time matters in multiple sclerosis. Multiple Sclerosis and Related Disorders, 9[Suplemento], S5-S48. http://dx.doi.org/10.1016/j.msard.2016.07.003

Goldenberg, M. M. (2012). Multiple sclerosis review. Pharmacy and Therapeutics, 37(3), 175-184.

Grech, L. B., Kiropoulos, L. A., Kirby, K. M., Butler, E., Paine, M., \& Hester, R. (2016). Coping mediates and moderates the relationship between executive functions and psychological adjustment in multiple sclerosis. Neuropsychology, 30(3), 361-376. http://dx.doi.org/10.1037/neu0000256

Haase, V. G., Lacerda, S. S., Lima, E. P., \& Lana-Peixoto, M. A. (2005). Desenvolvimento bem-sucedido com esclerose múltipla: um ensaio em psicologia positiva. Estudos de Psicologia, 10(2), 295-304.

Holland, J. M. (2014). Elisabeth Kübler-Ross. Em M. J. Brennan (Ed.), The A-Z of death and dying: Social, medical, and cultural aspects (pp. 286-288). doi: 10.13140/RG.2.1.3863.2401
Inslegers, R., Vanheule, S., Meganck, R., Debaere, V., Trenson, E., Desmet, M., \& Roelstraete, B. (2012). The assessment of the social cognition and object relations scale on TAT and interview data. Journal of Personality Assessment, 94(4), 372-379. http://dx.doi.org/10.1080/00223891.2012.662187

Kubler-Ross, E., \& Kessler, D. (2005). On grief and grieving: Finding the meaning of grief through the five stages of loss. New York: Scribner.

Kubler-Ross, E., \& Kessler D. (2000). Life lessons: Two experts on death and dying teach us about the mysteries of life and living. New York: Scribner.

Kübler-Ross, E. (2008). Sobre a morte e o morrer. São Paulo: Martins Fontes.

Lazarus, R. S., \& Folkman, S. (1984). Stress, appraisal and copping. New York: Springer PublishingCompany.

Parkes, C. M. (1998). Luto: Estudos sobre a perda na vida adulta. São Paulo: Summus.

Murray, H.A. (2005). Teste de Apercepção Temática - T. A. T. [Adaptado e ampliado por Maria Cecília Vilhena M. Silva] ( $3^{\mathrm{a}}$ ed.). São Paulo: Casa do Psicólogo.

Santos, C. T., \& Sebastiani, R. W. (2001). Acompanhamento psicológico à pessoa portadora de doença crônica. Em V. A. Angerami-Camon (Org.), E a psicologia entrou no hospital (pp. 147-176). São Paulo: Pioneira Thomson Learning.

Scaduto, A. A., \& Barbieri, V. (2013). Em defesa do TAT: Uma revisão crítica das pesquisas sobre o teste no Brasil. Avaliação Psicológica, 12(3), 299-305.

Scaduto, A. A. (2016). O Teste de Apercepção Temática (TAT) em adultos: Dados normativos para o sistema morvaliano. Tese de Doutorado, Faculdade de Filosofia, Ciências e Letras de Ribeirão Preto, Universidade de São Paulo, Ribeirão Preto.

Schmidt, E., \& Mata, G. F. (2008). A relação médico-paciente e as condições de cronicidade. Revista Brasileira de Clínica Médica, 6, 191-193.

Simonetti, A. (2011). Manual de psicologia hospitalar: O mapa da doença. São Paulo: Casa do Psicólogo.

Ucelli, M. M., Traversa, S., Trojano, M., Viterbo, R. G., Ghezzi, A., \& Signori, A. (2013). Lack of information about multiple sclerosis in children can impact parents' sense of competency and satisfaction within the couple. Journal of the Neurological Sciences, 324, 100-105. http://dx.doi.org/10.1016/j.jns.2012.10.010

Recebido em: 01/12/2013 Primeira decisão editorial em: 27/03/2017 Aceito em: 24/05/2017 